\title{
Preclinical and clinical studies of photobiomodulation therapy for macular oedema
}

\author{
Weiyong Shen ${ }^{1} \cdot$ Kelvin Yi Chong Teo ${ }^{1,2} \cdot$ John P. M. Wood ${ }^{3} \cdot$ Anagha Vaze $^{1,4} \cdot$ Glyn Chidlow $^{3} \cdot$ Jack Ao $^{3} \cdot$ So-Ra Lee $^{1}$. \\ Michelle X. Yam ${ }^{1}$ • Elisa E. Cornish ${ }^{1,4}$. Samantha Fraser-Bell ${ }^{1,4}$ • Robert J. Casson ${ }^{3}$. Mark C. Gillies ${ }^{1,4}$
}

Received: 19 November 2019 / Accepted: 16 April 2020 / Published online: 14 July 2020

(C) Springer-Verlag GmbH Germany, part of Springer Nature 2020

\begin{abstract}
Aims/hypothesis Diabetic macular oedema (DME) is the leading cause of visual impairment in people with diabetes. Intravitreal injections of vascular endothelial growth factor inhibitors or corticosteroids prevent loss of vision by reducing DME, but the injections must be given frequently and usually for years. Here we report laboratory and clinical studies on the safety and efficacy of $670 \mathrm{~nm}$ photobiomodulation (PBM) for treatment of centre-involving DME.

Methods The therapeutic effect of PBM delivered via a light-emitting diode (LED) device was tested in transgenic mice in which induced Müller cell disruption led to photoreceptor degeneration and retinal vascular leakage. We also developed a purpose-built $670 \mathrm{~nm}$ retinal laser for PBM to treat DME in humans. The effect of laser-delivered PBM on improving mitochondrial function and protecting against oxidative stress was studied in cultured rat Müller cells and its safety was studied in pigmented and non-pigmented rat eyes. We then used the retinal laser to perform PBM in an openlabel, dose-escalation Phase IIa clinical trial involving 21 patients with centre-involving DME. Patients received 12 sessions of PBM over 5 weeks for 90 s per treatment at a setting of 25,100 or $200 \mathrm{~mW} / \mathrm{cm}^{2}$ for the three sequential cohorts of 6-8 patients each. Patients were recruited from the Sydney Eye Hospital, over the age of 18 and had centreinvolving DME with central macular thickness (CMT) of $>300 \mu \mathrm{m}$ with visual acuity of $75-35 \mathrm{Log}$ minimum angle of resolution ( $\log$ MAR) letters (Snellen visual acuity equivalent of 20/30-20/200). The objective of this trial was to assess the safety and efficacy of laser-delivered PBM at 2 and 6 months. The primary efficacy outcome was change in CMT at 2 and 6 months.

Results LED-delivered PBM enhanced photoreceptor mitochondrial membrane potential, protected Müller cells and photoreceptors from damage and reduced retinal vascular leakage resulting from induced Müller cell disruption in transgenic mice. PBM delivered via the retinal laser enhanced mitochondrial function and protected against oxidative stress in cultured Müller cells. Laser-delivered PBM did not damage the retina in pigmented rat eyes at $100 \mathrm{~mW} / \mathrm{cm}^{2}$. The completed clinical trial found a significant reduction in CMT at 2 months by $59 \pm 46 \mu \mathrm{m}\left(p=0.03\right.$ at $\left.200 \mathrm{~mW} / \mathrm{cm}^{2}\right)$ and significant reduction at all three settings at 6 months $\left(25 \mathrm{~mW} / \mathrm{cm}^{2}: 53 \pm 24 \mu \mathrm{m}, p=0.04 ; 100 \mathrm{~mW} / \mathrm{cm}^{2}: 129 \pm 51 \mu \mathrm{m}, p<0.01 ; 200 \mathrm{~mW} / \mathrm{cm}^{2}: 114 \pm 60 \mu \mathrm{m}, p<0.01\right)$. Laser-delivered PBM was well tolerated in humans at settings up to $200 \mathrm{~mW} / \mathrm{cm}^{2}$ with no significant side effects.
\end{abstract}

Weiyong Shen and Kelvin Yi Chong Teo contributed equally to this study.

Electronic supplementary material The online version of this article (https://doi.org/10.1007/s00125-020-05189-2) contains peer-reviewed but unedited supplementary material, which is available to authorised users.

Mark C. Gillies

mark.gillies@sydney.edu.au

Robert J. Casson

casson.robert@gmail.com

1 Save Sight Institute, Discipline of Ophthalmology, Sydney Medical School, The University of Sydney, 8 Macquarie Street, Sydney, NSW 2000, Australia
2 Singapore Eye Research Institute, Singapore National Eye Centre, Singapore, Republic of Singapore

3 Department of Ophthalmology and Visual Sciences, Adelaide Health and Medical Sciences Building, University of Adelaide, Adelaide, SA 5000, Australia

4 Sydney Eye Hospital, 8 Macquarie Street, Sydney, NSW 2000, Australia 


\section{Research in context}

\section{What is already known about this subject?}

- Diabetic macular oedema (DME) is caused by breakdown of the blood retinal barrier, leading to accumulation of fluid and photoreceptor degeneration

- Current treatments include intravitreal injections of vascular endothelial growth factor (VEGF) inhibitors or steroids, but both have adverse effects

- Photobiomodulation (PBM) at $670 \mathrm{~nm}$, delivered through a light-emitting diode (LED) device, has emerged as a potential treatment for retinal degeneration, including early diabetic retinopathy in rodents and in four cases of non-centre-involving DME in humans

What is the key question?

- Is PBM safe and effective in treating centre-involving DME?

What are the new findings?

- LED-delivered PBM protected Müller cells and photoreceptors and reduced retinal vascular leakage in transgenic mice with features of DME

- $\quad$ PBM delivered with a retinal laser enhanced mitochondrial function and protected against oxidative stress in cultured Müller cells

- Laser-delivered PBM appeared safe and reduced central macular thickness in an open-label Phase lla clinical trial involving 21 eyes with centre-involving DME

How might this impact on clinical practice in the foreseeable future?

- Future research is warranted to study whether PBM can be used as an adjunct therapy to improve the effectiveness and reduce the frequency of intravitreal injections of VEGF inhibitors

Conclusions/interpretation PBM results in anatomical improvement of DME over 6 months and may represent a safe and noninvasive treatment. Further testing is warranted in randomised clinical trials.

Trial registration ClinicalTrials.gov NCT02181400

Keywords Clinical trial · Diabetic macular oedema · Müller cell · Photobiomodulation · Photoreceptor · Transgenic mice

$\begin{array}{ll}\text { Abbreviations } \\ \text { BCVA } & \text { Best corrected visual acuity } \\ \text { BRB } & \text { Blood retinal barrier } \\ \text { CMT } & \text { Central macular thickness } \\ \text { DME } & \text { Diabetic macular oedema } \\ \text { EC } & \text { Half-maximal response } \\ \text { ETDRS } & \text { Early Treatment Diabetic Retinopathy Study } \\ \text { FFA } & \text { Fundus fluorescein angiography } \\ \text { GS } & \text { Glutamine synthetase } \\ \text { JC-1 } & \text { 5,5',6,6'-Tetrachloro-1,1',3,3' tetraethylbenzimi- } \\ & \text { dazolylcarbocyanine iodide } \\ \text { LED } & \text { Light-emitting diode } \\ \text { LOCF } & \text { Last observation carried forward } \\ \text { LogMAR } & \text { Log minimum angle of resolution } \\ \text { MTT } & 3 \text {-(4,5-Dimethylthiazol-2-yl)-2,5-diphenyltetra- } \\ & \text { zolium bromide } \\ \text { OCR } & \text { Oxygen consumption rate } \\ \text { PBM } & \text { Photobiomodulation }\end{array}$

\author{
PNA Peanut agglutinin \\ SD-OCT Spectral domain optical coherence tomography \\ tBH tert-Butyl hydroperoxide \\ VEGF Vascular endothelial growth factor
}

\section{Introduction}

Diabetic macular oedema (DME), the leading cause of visual impairment in people with diabetes $[1,2]$, is characterised by accumulation of fluid in the macula due to breakdown of the blood retinal barrier (BRB). The inner BRB is formed by tight junctions between endothelial cells of retinal vessels [3, 4]. Hyperglycaemia results in oxidative stress, inflammation, and upregulation of vascular endothelial growth factor (VEGF), cytokines and chemokines, leading to breakdown of the BRB $[3,5]$. This in turn results in fluid accumulation 
within the retina and eventually irreversible visual impairment from damage to photoreceptors [3].

Intravitreal injections of VEGF inhibitors are currently the first line treatment for DME [6, 7]. Anti-VEGF therapies can be extremely effective in treating vascular leakage, but they usually require many injections over several years before the disease stabilises. They may also be associated with uncommon but serious adverse effects, including endophthalmitis and a possible increased risk of myocardial infarction and cerebrovascular accidents [6-8]. Intravitreal injection of corticosteroids, generally reserved for second line treatment, is limited by their side effects of causing cataract and elevated intraocular pressure [6].

Photobiomodulation (PBM) has recently emerged as a potential treatment for a variety of neurological conditions $[9,10]$. This technique involves exposure of tissue to a low intensity of light at wavelengths ranging from $600 \mathrm{~nm}$ to $1000 \mathrm{~nm}$. The benefits of PBM for retinal diseases have been described in animal models of retinal conditions including age-related macular degeneration, retinopathy of prematurity and diabetic retinopathy $[9,11]$. PBM has been reported to inhibit superoxide production and other aspects of local inflammation in the retina [11-14]. Previous studies indicated that a brief daily application of PBM at a wavelength of $670 \mathrm{~nm}$ through a light-emitting diode (LED) device inhibited the molecular processes implicated in diabetic retinopathy in rodents [13-15] and reduced retinal thickness in four patients with non-centre-involving DME [16].

Here we report laboratory and clinical studies of PBM for the treatment of DME. First, we studied the effects of LED-delivered PBM on protecting Müller cells and photoreceptors from damage and reducing retinal vascular leakage in transgenic mice with induced Müller cell disruption [17, 18]. Next, we developed a purpose-built $670 \mathrm{~nm}$ retinal laser for PBM and outline the mechanisms and protective effects of laser-delivered PBM in vitro. We have studied the safety of laser-delivered PBM in rats before testing it clinically. Last, we used the purpose-built retinal laser to treat 21 eyes with centre-involving DME in an open-label dose-escalation Phase IIa clinical trial.

\section{Methods}

\section{Animals}

Animal studies were approved by the institutional animal ethics committees and conform with the Association for Research in Vision and Ophthalmology (ARVO) statement for the Use of Animals in Ophthalmic and Vision Research. Transgenic mice for induced Müller cell disruption were generated as described previously [17-19]. Sprague Dawley rat pups and adults and Dark Agouti adult rats were also used in this study. Both male and female animals were used in this study. Mice in the same litter were randomly assigned based on their odd or even animal identification numbers for PBM or sham treatment. The experimenters were blind to outcome assessments. See electronic supplementary material (ESM) Methods for details.

\section{LED-delivery PBM in transgenic mice}

The effect of PBM on photoreceptor protection was studied immediately after induced Müller cell disruption (Fig. 1a). Briefly, after pupil dilation, a WARP10 LED device (Quantum Devices, Barneveld, WI, USA) was held $1 \mathrm{~cm}$ in front of the eyes of unsedated mice (ESM Fig. 1). Each mouse received two cycles of PBM per day for 9 days, with both eyes treated at $40 \mathrm{~mW} / \mathrm{cm}^{2}$ for $90 \mathrm{~s} / \mathrm{cycle}$. Sham-treated mice were exposed to ambient light only. In order to study the effect of PBM on retinal vascular leakage, we performed fundus fluorescein angiography (FFA) to confirm vascular leakage 3 months after induced Müller cell disruption and then applied daily PBM or sham treatment for 9 days (Fig. 2a). Changes in vascular leakage was studied by FFA and quantitative analysis of retinal permeability to fluorescent dextran $[17,18,20]$. Transgenic mice that did not develop retinal vascular leakage at 3 months after intraperitoneal injections of tamoxifen were excluded from the leakage study. See ESM Methods.

\section{Immunostaining using retinal wholemounts and frozen sections}

Photoreceptor mitochondrial membrane potential was studied

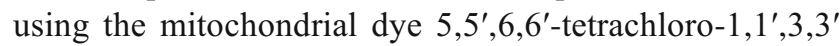
tetraethylbenzimidazolylcarbocyanine iodide (JC-1) as described previously [21]. Briefly, retinas were freshly prepared and incubated in pre-warmed neurobasal medium containing $25 \mu \mathrm{g} / \mathrm{ml} \mathrm{JC}-1$ (Invitrogen, Australia) for $45 \mathrm{~min}$. After washing in PBS, retinas were fixed with $4 \%$ paraformaldehyde, counterstained with Hoechst 33342 and flatmounted with photoreceptor facing up for confocal fluorescent microscopy. We also performed peanut agglutinin (PNA) staining to study cone photoreceptor apical processes in fixed retinal wholemounts and immunostaining for glutamine synthetase (GS, Merck, Australia; \#MAB302, 1:100) on frozen sections to study Müller cells as described previously [17-19]. Images from single plate confocal fluorescent microscopy were analysed using Image J [17-19].

\section{Laser-delivered PBM system}

As LED-delivered PBM emits non-coherent scattered irradiation, which may become a barrier to clinical translation, we developed a custom-designed, slit lamp microscope-mounted Integre retinal laser (Ellex Medical Lasers, Adelaide, Australia) to deliver precise PBM (ESM Fig. 2). This retinal laser emits a $670 \mathrm{~nm}$ laser beam with $4.5 \mathrm{~mm}$ diameter at a power density ranging from 25 to $500 \mathrm{~mW} / \mathrm{cm}^{2}$. 



Fig. 1 LED-delivered PBM enhanced photoreceptor mitochondrial membrane potential and attenuated photoreceptor degeneration. (a) Diagram outlining LED-delivered PBM in transgenic mice immediately after induced Müller cell disruption. (b-g) Evaluation of photoreceptor mitochondrial membrane potential in transgenic mice receiving sham treatment (b-d) or daily PBM for 9 days $(\mathbf{e}-\mathbf{g})$ by staining retinal wholemounts with the mitochondrial dye JC-1 (representative images shown). En face images were taken at the level of the photoreceptor inner segments. Arrows indicate loss of photoreceptor inner segments caused by induced Müller cell disruption. (h) Quantitative analysis of the ratio of red/green fluorescent intensity of JC-1 staining in retinal wholemounts from wild-type and transgenic mice receiving sham or PBM treatment. A shift of the light emission from $525 \mathrm{~nm}$ (green) towards $590 \mathrm{~nm}$ (red) indicates an increased membrane potential. (i-l) Representative retinal wholemounts stained with PNA. (m) Quantitative analysis of PNAstained cone photoreceptor apical processes. $n=6 /$ group in wild-type mice and $n=10$ /group in transgenic mice, respectively, receiving sham treatment or PBM in (b-m). (n-p) Representative immunostaining for GS. Arrows point to protrusion of photoreceptor nuclei into the subretinal space due to the loss of Müller cells. (q) Quantitative analysis of $\mathrm{GS}^{+}$ Müller cells on frozen sections from wild-type and transgenic mice receiving sham or PBM treatment; $n=8 /$ group in wild-type and transgenic mice receiving sham treatment and $n=6$ in transgenic mice receiving PBM. $* p<0.05$ and $* * p<0.01$, analysed by two-way ANOVA with multiple comparisons. Data were expressed as mean \pm SEM. Scale bars, $50 \mu \mathrm{m}$. Ctl, wild-type control mice; TG, transgenic; TMX, tamoxifen

\section{Metabolic analysis and immunocytochemistry in Müller cells treated with laser-delivered PBM}

Müller cells were isolated from 2-4-day-old rat pups as described previously [22]. Cultured cells were treated with PBM by placing plates on a warmed horizontal platform attached to the chin rest in the slit lamp retinal laser system (ESM Fig. 2). Treatments were applied centrally to individual wells at $100 \mathrm{~mW} / \mathrm{cm}^{2}$ for $90 \mathrm{~s}$. Cell respiratory activity was analysed by 3-(4,5-dimethylthiazol-2-yl)-2,5-diphenyltetrazolium bromide (MTT) assays [22]. The mitochondrial respiratory activity was further measured in detail using a Seahorse 


\section{a}

Daily LED-PBM,
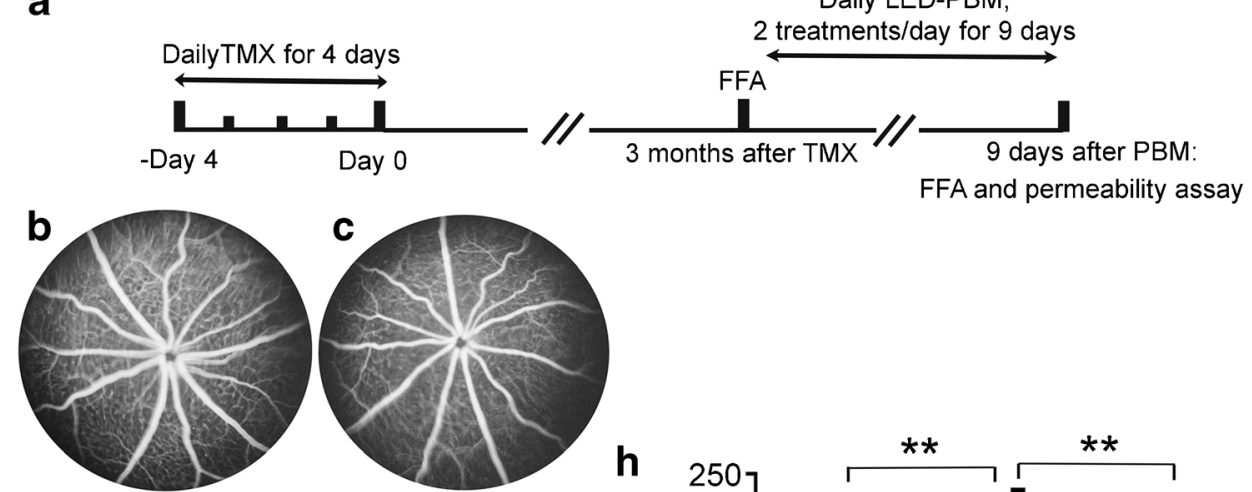
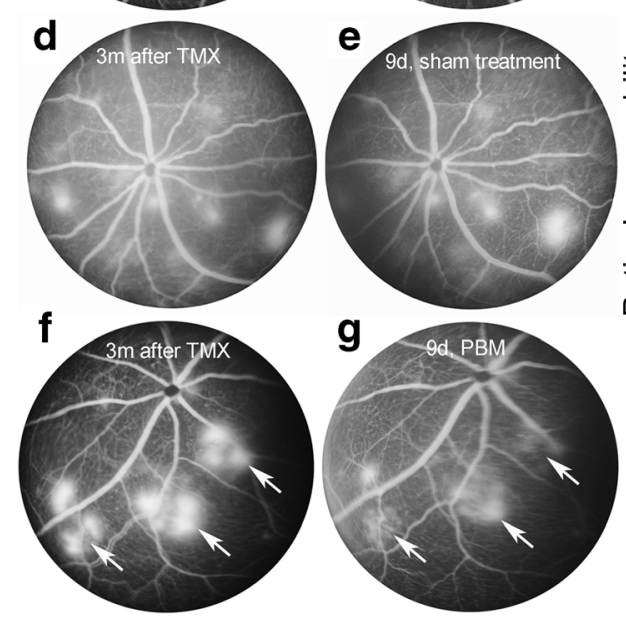

Fig. 2 PBM delivered via LED reduced retinal vascular leakage in transgenic mice with induced Müller cell disruption. (a) Diagram outlining LED-delivered PBM to treat retinal vascular leakage commenced 3 months after induced Müller cell disruption. (b-g) Representative FFA images from wild-type (b, c) and transgenic (d-g) mice before and 9 days after PBM or sham treatment. (b, c) PBM in wild-type mice did not affect the normal retinal vascular integrity. (d, e) Vascular leakage in a transgenic mouse receiving sham treatment remained relatively unchanged during the study

XFe96 extracellular flux analyser (Agilent Technologies Australia, Mulgrave, VIC, Australia). Alamar Blue cell viability assays were performed to study whether PBM protects Müller cells from injury. We performed immunocytochemistry using an antibody against vimentin (Dako, 1:5000) to study whether PBM alters Müller cell morphology. See ESM Methods for details.

\section{Live cell imaging to assess mitochondrial respiratory activity}

Sham- or laser PBM-treated cells were exposed to a medium containing $5 \mu \mathrm{mol} / 1$ MitoSOX Red dye (ThermoFisher Scientific, Scoresby, VIC, Australia) for $10 \mathrm{~min}$. This dye is oxidised by superoxide production in the mitochondria of live cells to form a product that is highly fluorescent upon binding to nucleic acids. Cells were co-labelled with the MitoSOX Red fluorescence and the nuclear Hoechst dye 33,342 for confocal fluorescent microscopy. See ESM Methods.



period. (f, g) Daily PBM for 9 days reduced retinal vascular leakage (arrows). (h) Quantitative measurement of retinal vascular permeability to fluorescently labelled dextran indicates that PBM significantly reduced retinal vascular leakage. $* * p<0.01$, analysed by two-way ANOVA with multiple comparisons test. $n=6 /$ group in wild-type mice receiving sham treatment and $n=9$ and 10 in transgenic mice receiving sham treatment or $\mathrm{PBM}$, respectively. Data were expressed as mean $\pm \mathrm{SEM}$. Ctl, wild-type control mice; d, days; m, months; TG, transgenic; TMX, tamoxifen

\section{Laser-delivered PBM in rats}

The safety of laser-delivered PBM was studied in Sprague Dawley and Dark Agouti rats after treating retinas with 100 or $500 \mathrm{~mW} / \mathrm{cm}^{2}$ every 2 days for 1 week. Spectral domain optical coherence tomography (SD-OCT) was performed concurrently with fundus imaging at baseline and 1 week after the last treatment. Eyes were enucleated and fixed for histology and immunostaining 1 week after the last PBM. See ESM Methods.

\section{Human ethics approval, participants and treatments in clinical trial}

The clinical study was approved by institutional human ethics committees and adhered to the tenets of the Declaration of Helsinki. All study participants were given informed consent. Twenty-one participants aged $\geq 18$ years with DME and central macular thickness (CMT) $>300 \mu \mathrm{m}$ on SD-OCT and 
visual acuity of 75-35 Log minimum angle of resolution (logMAR) letters (Snellen visual acuity equivalent of 20/30 $20 / 200$ ) were allocated sequentially into three groups based on the power for PBM (Table 1). A total of 7, 6 and 8 participants were recruited into group $1\left(25 \mathrm{~mW} / \mathrm{cm}^{2}\right)$, group $2(100 \mathrm{~mW} /$ $\left.\mathrm{cm}^{2}\right)$ and group $3\left(200 \mathrm{~mW} / \mathrm{cm}^{2}\right)$, respectively. We included a central masked area of $1.0 \mathrm{~mm}$ diameter within the $4.5 \mathrm{~mm}$ diameter treatment zone to spare the fovea. PBM was applied through a standard fundus contact lens with the patient fixating on the central aiming beam. Each patient received 12 sessions of PBM over 5 weeks. See ESM Methods.

\section{Rescue treatment and study outcomes}

Standard of care treatment for DME was allowed at the discretion of the treating physician. The primary endpoint to ascertain the efficacy of PBM was change in CMT from baseline to 2 and 6 months after treatment. Changes in CMT between groups at 2 and 6 months were also assessed. Secondary outcome measures included best corrected visual acuity (BCVA) 2 and 6 months after treatment and the proportion of eyes that received rescue treatment.

\section{SD-OCT imaging in humans}

SD-OCT images were obtained on the Spectralis/HRA2 OCT (Heidelberg Engineering, Heidelberg, Germany). CMT for the nine Early Treatment Diabetic Retinopathy Study (ETDRS) subfields was obtained from automated segmentation using the Heidelberg Eye Explorer software (version 6.9.5; Heidelberg Engineering).

\section{Statistical analyses}

Results from preclinical studies are expressed as mean \pm SEM. Data were analysed using an unpaired two-tailed Student's $t$ test or ANOVA with a post hoc Tukey's or Bonferroni's correction for multiple comparisons. The sample size for the clinical study was based on a paired $t$ test such that each of the three treatment groups had an $80 \%$ power to detect a change from baseline CMT of $100 \mu \mathrm{m}$ with an SD of $50 \mu \mathrm{m}$ at the 6 month time point with an $\alpha$ level set at 0.01 to allow for comparisons between groups to maintain the significance level within 0.05 when comparing groups to determine the most effective dosage. Descriptive data from clinical studies are presented as mean $(95 \% \mathrm{CI})$, mean $\pm \mathrm{SD}$, median or number (percentage). Student's $t$ test, Wilcoxon rank sum and $\chi^{2}$ tests were used where appropriate to compare baseline characteristics between groups. A repeated ANCOVA model across repeated observations at month 2 and 6 with the baseline measures as a covariate was used. Last observation carried forward (LOCF) analysis was applied as the last measure prior to any additional treatment in addition to PBM therapy. Analyses were conducted using R V3.3.1 [23]. A $p$ value $<0.05$ was regarded as statistically significant.

\section{Results}

\section{Preclinical studies}

LED-delivered PBM enhanced photoreceptor mitochondrial membrane potential and protected Müller cells and photoreceptors from injury Photoreceptor mitochondrial membrane potential was studied by staining retinal wholemounts with
Table 1 Baseline characteristics of 21 participants with centreinvolving DME

\begin{tabular}{lllll}
\hline Characteristic & Group 1 $(n=7)$ & Group 2 $(n=6)$ & Group 3 $(n=8)$ & $p$ value \\
\hline Age, years, mean (SD) & $65.1(4.6)$ & $64.6(3.6)$ & $61.7(3.7)$ & $0.21^{\mathrm{a}}$ \\
Sex, proportion male, $n(\%)$ & $6(85.7)$ & $6(85.7)$ & $5(71.4)$ & $0.73^{\mathrm{b}}$ \\
BCVA, logMAR letters, mean (SD) & $64.6(10.8)$ & $64.3(7.3)$ & $68.8(13.3)$ & $0.59^{\mathrm{a}}$ \\
Study eye, proportion right, $n(\%)$ & $3(42.9)$ & $3(42.9)$ & $2(28.6)$ & $0.81^{\mathrm{b}}$ \\
NPDR status & & & & $0.34^{\mathrm{b}}$ \\
$\quad$ Proportion mild, $n(\%)$ & $1(14.3)$ & $1(14.3)$ & $1(14.3)$ & \\
$\quad$ Proportion moderate, $n(\%)$ & $5(71.4)$ & $5(71.4)$ & $4(57.1)$ & \\
$\quad$ Proportion severe, $n(\%)$ & $1(14.3)$ & $1(14.3)$ & $2(28.6)$ & \\
CMT, $\mu \mathrm{m}$, mean $(\mathrm{SD})$ & $401.9(109.1)$ & $395.3(25.3)$ & $454.6(69.7)$ & $0.08^{\mathrm{a}}$ \\
\hline
\end{tabular}

Participants in groups 1-3 received total 12 sessions of laser-delivered PBM over 5 weeks at a setting of 25, 100 or $200 \mathrm{~mW} / \mathrm{cm}^{2}$, respectively, for $90 \mathrm{~s}$ per session

NPDR, non-proliferative diabetic retinopathy. Definition of NPDR status: mild NPDR, microaneurysms only; moderate NPDR, more than just microaneurysms but less than severe NPDR; severe NPDR, any of the following: $>20$ intraretinal haemorrhages in each of the four quadrants, definite venous beading in $\geq 2$ quadrants or prominent intraretinal microvascular abnormalities in $\geq 1$ quadrants

$p$ value derived from ANOVA $^{\mathrm{a}}$ and $\chi^{2}$ tests $^{\mathrm{b}}$ as appropriate 
the mitochondrial dye JC-1 (Fig. 1a-h). The cationic JC-1 dye shifts towards $525 \mathrm{~nm}$ (green) emission when the mitochondrial membrane depolarises, while increased membrane potential causes JC-1 monomers to form aggregates that shift the light emission towards $590 \mathrm{~nm}$ (red) [21, 24]. In transgenic mice receiving sham treatment, Müller cell disruption led to patchy loss of photoreceptor apical processes including the inner segments (Fig. 1b-d), while the surviving photoreceptor inner segments expressed strong green and weak red fluorescence after JC-1 staining, indicating a reduced mitochondrial membrane potential (Fig. 1b-d). PBM reduced the green fluorescence and increased red fluorescence at the photoreceptor inner segments, suggesting an enhanced mitochondrial membrane potential (Fig. 1e-g). Analysis of the ratio of red/


g

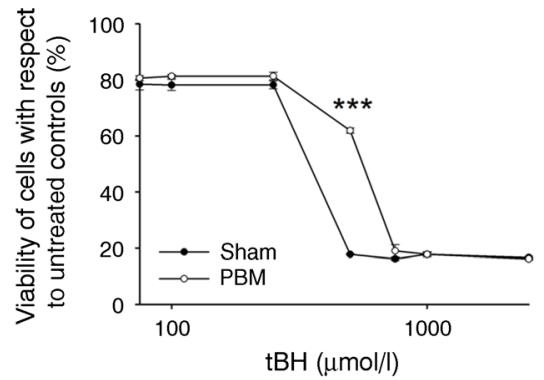

Fig. 3 Effect of laser-delivered PBM at $100 \mathrm{~mW} / \mathrm{cm}^{2}$ on cultured rat Müller cells. (a) Metabolic activity measured by MTT assays in cells treated with PBM relative to sham-treated controls showing that the metabolic activity was significantly elevated immediately after PBM and it remained elevated for at least $24 \mathrm{~h} ; n=4-6$ replicates per culture and 4 separate cultures. (b) Seahorse extracellular flux analyses of changes in OCR upon manipulations of cells with various compounds including oligomycin (O), carbonyl cyanide-4-phenylhydrazone (FCCP; F) and antimycin $\mathrm{A} /$ rotenone $(\mathrm{A} / \mathrm{R})$. (c-f) Changes in basal respiration (c), ATP-linked respiration (d), mitochondrial maximum respiration (e) and reserve capacity (f) $24 \mathrm{~h}$ post PBM. $n=7-16$ separate determinations in green JC-1 fluorescence indicated that PBM had little effect on the mitochondrial membrane potential in wild-type mice (ESM Fig. 3) but significantly increased the ratio of red/green JC-1 fluorescence in transgenic mice (Fig. 1h).

We next studied whether PBM protects Müller cells and photoreceptors from injury (Fig. 1i-q). PBM did not affect the pattern of PNA staining in wild-type mice but attenuated the loss of cone apical processes in transgenic mice (Fig. 1i-1). Quantitative analysis indicated that the PNA-stained area was similar between PBM- and sham-treated eyes in wild-type mice but significantly larger in transgenic mice receiving PBM than sham-treated mice (Fig. 1m). Analysis of $\mathrm{GS}^{+}$ Müller cells indicated that the number of Müller cells was significantly reduced in transgenic mice receiving sham
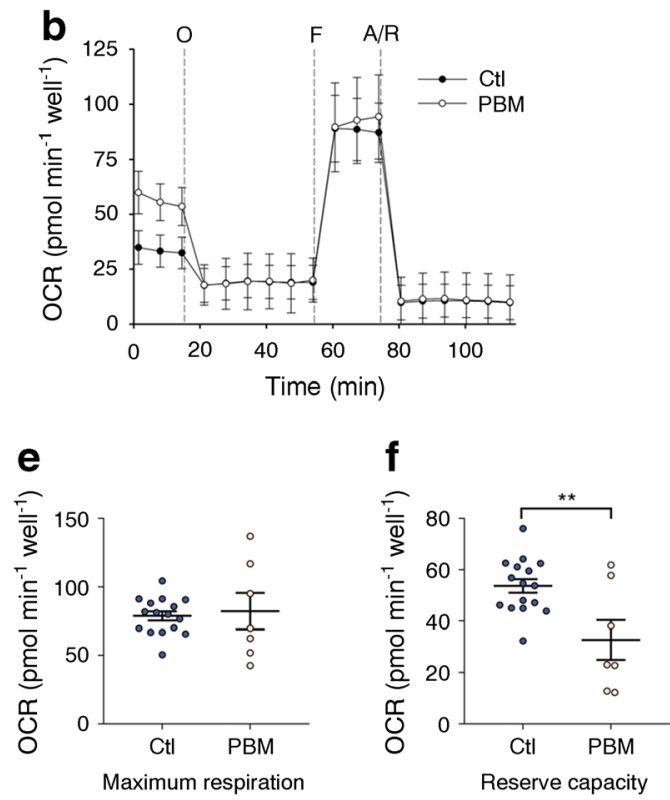

(b-f). (g) AlamarBlue cell viability assays indicate that PBM significantly protected Müller cells from oxidative stress-induced death after treating Müller cells with $\mathrm{tBH}$ at concentrations ranging $250-750 \mu \mathrm{mol} / 1 ; n=4-6$ replicates per culture and 4 separate cultures. ${ }^{*} p<0.05, * * p<0.01$ and $* * * p<0.001$ vs sham-treated cells. Data were expressed as mean \pm SEM and analysed by Student's unpaired $t$ tests in $(\mathbf{a}, \mathbf{c}-\mathbf{g})$. The comparison was conducted against sham-treated controls at each time-point in (a). All determinations were carried out $24 \mathrm{~h}$ after culture and sham-treated controls were used for comparison with PBM-treated groups for each concentration of tbH. Ctl, sham-treated control 
treatment compared with wild-type controls but the number of Müller cells in PBM-treated transgenic mice was significantly higher than that in the sham-treated group (Fig. 1n-q).

PBM reduced retinal vascular leakage in transgenic mice We next studied the effect of LED-delivered PBM on retinal vascular leakage (Fig. 2a-h). PBM in wild type mice did not affect the integrity of the normal vasculature (Fig. 2b, c). Transgenic mice developed focal intense vascular leak 3 months after Müller cell disruption (Fig. 2d, f) and the vascular leak remained relatively unchanged during the study period (Fig. 2d, e). However, PBM reduced retinal vascular leakage revealed by FFA (Fig. 2f, g) and significantly decreased the extravasation of fluorescently labelled dextran (Fig. 2h).

\section{Laser-delivered PBM enhanced mitochondrial function and} protected Müller cells against oxidative stress MTT assays indicated that cell metabolic activity was significantly increased immediately after PBM in Müller cells and it continued to rise for $24 \mathrm{~h}$ (Fig. 3a). Seahorse extracellular flux analysis indicated that PBM significantly increased the levels of basal and ATP-linked cellular respiration (Fig. 3b-d) while the maximum respiration remained unchanged (Fig. 3b, e). These effects were accompanied by reduced reserve respiratory capacity (Fig. 3f).

We performed AlamarBlue cell viability assays to study whether PBM protected Müller cells in vitro (Fig. 3g). The half-maximal response $\left(\mathrm{EC}_{50}\right)$ to tert-butyl hydroperoxide (tBH)-induced cell injury was approximately $375 \mu \mathrm{mol} / 1$ in sham-treated rat Müller cells. PBM $24 \mathrm{~h}$ prior to $\mathrm{tBH}$ challenge elevated the $\mathrm{EC}_{50}$ of $\mathrm{tBH}$ to approximately $650 \mu \mathrm{mol} / \mathrm{l}$. The number of viable Müller cells was significantly higher in the PBM-treated group than that in the sham-treated group after challenging cells with $500 \mu \mathrm{mol} / \mathrm{l} \mathrm{tBH}$ for $24 \mathrm{~h}$ (Fig. $3 \mathrm{~g}$ ).

Laser-delivered PBM did not affect the basic cell morphology and enhanced mitochondrial respiratory activity in Müller cells $\mathrm{PBM}$ delivered up to $500 \mathrm{~mW} / \mathrm{cm}^{2}$ did not affect the Müller cell morphology (Fig. 4a). Cellular respiratory function was probed using MitoSOX Red (Fig. 4b, c). Immediately after PBM at $100 \mathrm{~mW} / \mathrm{cm}^{2}$, incubating Müller
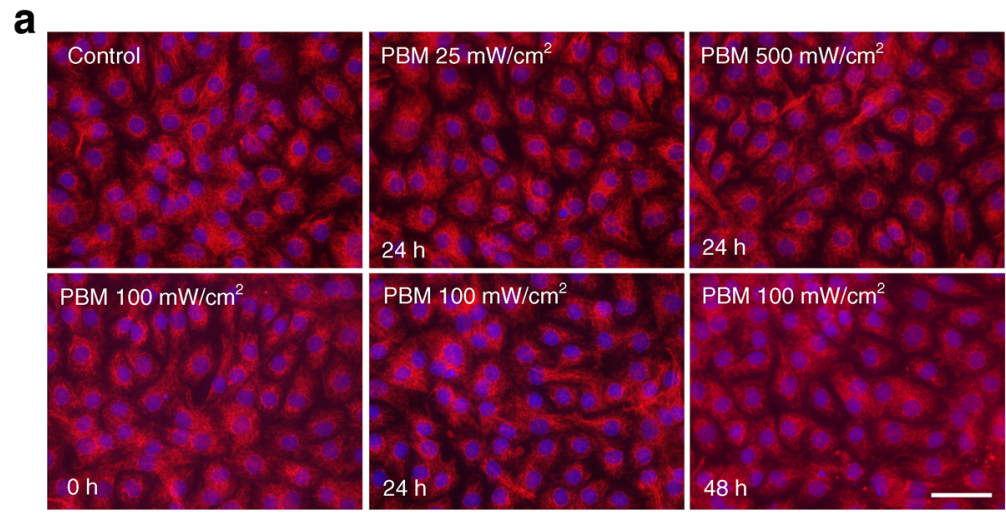

b


C

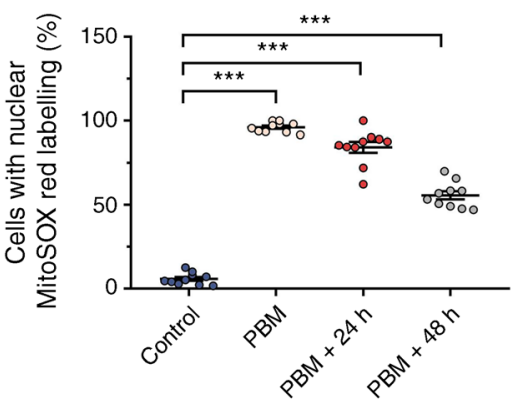

Fig. 4 Effects of laser-delivered PBM on basic cell morphology and cellular respiratory function in cultured rat Müller cells. (a) Representative images from 10 assessments after labelling cells with vimentin to show heterogeneity and disseminate any morphological changes after PBM. Müller cells showed a similar appearance $24 \mathrm{~h}$ after $\mathrm{PBM}$ at 25,100 or $500 \mathrm{~mW} / \mathrm{cm}^{2}$. Cells treated at $100 \mathrm{~mW} / \mathrm{cm}^{2}$ were also morphologically similar $48 \mathrm{~h}$ post PBM. (b, c) Representative live cell imaging after incubating Müller cells with $5 \mu \mathrm{mol} / 1$ MitoSOX Red for $10 \mathrm{~min}$. Increased mitochondrial activity was observed immediately after PBM and this effect lasted for 24-48 h. Controls were sham-treated cells. DAPI and Hoechst 33342 (blue) were used to stain cell nuclei in (a) and $(\mathbf{b}, \mathbf{c})$, respectively. Data were expressed as mean \pm SEM. $* * * p<0.001$, by one-way ANOVA plus Tukey's post hoc test; $n=10$ determinations, from separate cultures; scale bars, $50 \mu \mathrm{m}$ 
cells with MitoSOX Red for 10 min revealed almost a complete co-localisation of red fluorescence with nuclear blue labelling, indicating a very strong activity in mitochondrial oxidative phosphorylation. The percentage of cell nuclei positive for MitoSOX Red decreased over time but was still significantly higher than the sham-treated group $24 \mathrm{~h}$ and $48 \mathrm{~h}$ after PBM (Fig. 4c). These results indicate that PBM increased Müller cell mitochondrial respiration.

Laser-delivered PBM had a defined safety profile in pigmented eyes We studied the safety of laser-delivered PBM in pigmented and non-pigmented rat eyes. None of the pigmented eyes from sham- ( $n=6$, data not shown) or $100 \mathrm{~mW} / \mathrm{cm}^{2}(n=7)$ treated groups displayed any abnormalities on SD-OCT, fundus imaging, FFA or histology (Fig. 5ai; ESM Fig. 4). However, by 7 days post PBM, 4 of 10 pigmented eyes treated with $500 \mathrm{~mW} / \mathrm{cm}^{2}$ showed fundus and SD-OCT changes (Fig. 5j, k) although the retinal vasculature appeared normal (Fig. 51). In the affected regions, the retinal thickness was reduced from $247.8 \pm 11.0 \mu \mathrm{m}$ to 166.8 $\pm 11.6 \mu \mathrm{m}$ and the outer nuclear layer was essentially obliterated and not measurable by SD-OCT. Histological examination confirmed the findings from SD-OCT (Fig. 5d-i, m-r). $\mathrm{PBM}$ at $500 \mathrm{~mW} / \mathrm{cm}^{2}$ did not damage non-pigmented retinas (data not shown).

\section{Clinical studies}

Baseline characteristics There was no significant difference in baseline characteristics among the three groups treated with laser-delivered PBM at 25,100 or $200 \mathrm{~mW} / \mathrm{cm}^{2}$ (Table 1).

Primary outcome measures: changes in CMT There was an overall reduction in CMT at month 2 and 6 with LOCF in eyes receiving rescue treatment. Changes in CMT were not significantly different between treatment groups at month 2 . There was a significantly greater reduction in CMT in groups $2\left(100 \mathrm{~mW} / \mathrm{cm}^{2}\right)$ and $3\left(200 \mathrm{~mW} / \mathrm{cm}^{2}\right)$ than in group 1


Fig. 5 Changes in the retina of pigmented rats treated with laser-delivered PBM. (a-i) Representative images from 7 retinas treated with PBM at $100 \mathrm{~mW} / \mathrm{cm}^{2}$. There was no discernible alteration in the fundus image or SD-OCT between baseline pre-PBM (a) and 7 days post PBM (b). FFA post treatment appeared normal (c). Histology revealed no discernible injury to photoreceptors either superior or inferior to the optic nerve head (d-f) and no upregulation of glial fibrillary acidic protein (GFAP) by Müller cells $(\mathbf{g}-\mathbf{i})$. $(\mathbf{j}-\mathbf{r})$ Representative images from 4 out of 10 retinas showing damage after PBM at $500 \mathrm{~mW} / \mathrm{cm}^{2}$. When compared with baseline (j), total retinal thickness was reduced from $245 \mu \mathrm{m}$ to $176 \mu \mathrm{m}$ and thickness of the ONL was reduced from $54 \mu \mathrm{m}$ to $<5 \mu \mathrm{m}$ by laser treatment at the point of measurement (white arrow, insert in $\mathbf{k}$ ), a location

which displayed abnormal pigmentary changes on the fundus image (yellow arrow, k). The FFA image appeared normal despite having fundus and SD-OCT changes (l). Histology revealed localised destruction of photoreceptor nuclei and inner/outer segments in the region superior to the optic nerve head (m, n, arrow), accompanied by increased expression of GFAP by Müller cells overlying and immediately adjacent to the treated area (p, $\mathbf{q}$, arrow). On the inferior side of the optic nerve head, there was no injury or upregulation of glial markers $(\mathbf{o}, \mathbf{r})$. The scale bar in (r) applies to (d-i) and (m-q), where: $\mathbf{d}, \mathbf{g}, \mathbf{m}, \mathbf{p}, 250 \mu \mathrm{m} ; \mathbf{e}, \mathbf{f}, \mathbf{h}, \mathbf{i}, \mathbf{n}, \mathbf{o}, \mathbf{q}$, $\mathbf{r}, 50 \mu \mathrm{m}$. ' $\mathrm{S}$ ' and ' $\mathrm{I}$ ' in $(\mathbf{d}, \mathbf{g}, \mathbf{m}, \mathbf{p})$ represent superior and inferior, respectively. GCL, ganglion cell layer; INL, inner nuclear layer; ONL, outer nuclear layer 
Table 2 Outcomes 2 and 6 months after laser-delivered PBM

\begin{tabular}{|c|c|c|c|c|c|}
\hline & Group $1(n=7)$ & Group $2(n=6)$ & Group $3(n=8)$ & $p$ value $^{\mathrm{a}}$ & Overall \\
\hline \multicolumn{6}{|l|}{2 month outcomes } \\
\hline $\mathrm{CMT}, \mu \mathrm{m}$, mean $(\mathrm{SD})$ & $376.3(46.3)$ & $366.0(54.0)$ & $388.7(46.8)$ & 0.85 & $377.0(47.2)$ \\
\hline CMT change, $\mu \mathrm{m}$, mean $(\mathrm{SD})$ & $-25.2(35.1)$ & $-29.9(38.6)$ & $-58.9(45.5)$ & 0.08 & $-39.4(31.7)$ \\
\hline$p$ value ${ }^{\mathrm{b}}$ & 0.18 & 0.12 & 0.03 & - & 0.04 \\
\hline BCVA, logMAR letters, mean (SD) & $68(11)$ & $66(7)$ & $74(5)$ & 0.13 & $69(8)$ \\
\hline BCVA change, logMAR letters, mean (SD) & $4(2)$ & $2(4)$ & $6(13)$ & 0.74 & $4(7)$ \\
\hline$p$ value $^{\mathrm{b}}$ & 0.05 & 0.27 & 0.08 & - & 0.02 \\
\hline \multicolumn{6}{|l|}{6 month outcomes } \\
\hline $\mathrm{CMT}, \mu \mathrm{m}$, mean $(\mathrm{SD})$ & $355.5(70.0)$ & $308.2(35.1)$ & $342.0(38.5)$ & 0.75 & $317.0(45.0)$ \\
\hline CMT change, $\mu \mathrm{m}$, mean $(\mathrm{SD})$ & $-52.5(23.6)$ & $-128.6(51.4)$ & $-114.0(59.5)$ & 0.04 & $-87.8(45.7)$ \\
\hline$p$ value ${ }^{\mathrm{b}}$ & 0.04 & $<0.01$ & $<0.01$ & - & $<0.01$ \\
\hline BCVA, logMAR letters, mean (SD) & $70(10)$ & $63(15)$ & $70(20)$ & 0.55 & $68(15)$ \\
\hline BCVA change, logMAR letters, mean (SD) & $4(6)$ & $-2(7)$ & $-3(10)$ & 0.09 & $2(9)$ \\
\hline$p$ value $^{\mathrm{b}}$ & 0.06 & 0.38 & 0.25 & - & 0.49 \\
\hline
\end{tabular}

${ }^{\mathrm{a}}$ Test of significance by repeated measure ANCOVA model across repeated observations at month 2 and 6 with the baseline measures, including CMT and BCVA as covariates

${ }^{\mathrm{b}}$ Test of significance by paired $t$ test 2 and 6 months after PBM vs baseline in each treatment group

$\left(25 \mathrm{~mW} / \mathrm{cm}^{2}\right)$ at month 6 post treatment. Changes in CMT are summarised in Table 2 and Fig. 6a, b. Examples of various outcomes after PBM treatment are shown in Figs 7, 8, and 9.

Secondary outcome measures: changes in BCVA The mean BCVA (SD) increased by 4.0 (7.1) logMAR letters $(p=$ 0.02 ) from baseline to month 2 . However, the overall visual acuity gain was not sustained at month 6 ( $p=$ 0.49). Changes in BCVA are summarised in Table 2 and Fig. 6c, d.

Rescue treatments Rescue treatment was administered to five eyes that were deemed to have worsening DME at the physician's discretion ( 3 eyes from group 1, 2 eyes from group 2 and none from group 3). All rescue treatments were administered 2 months post PBM, thus allowing the primary analysis to be carried out in all eyes. Six month outcomes were taken as LOCF prior to the rescue treatment. Of the three eyes receiving rescue treatment in group 1, two eyes were treated about 3 months from baseline (one eye was treated with bevacizumab and the other eye with focal laser), and one eye was treated with bevacizumab about 4 months from baseline. Of the two eyes receiving rescue treatment in group 2 , one eye was treated with bevacizumab about 4 months from baseline, and the other eye was treated with dexamethasone implant about 5 months from baseline.

Safety There were no adverse effects in eyes treated with laserdelivered $\mathrm{PBM}$ at 25,100 or $200 \mathrm{~mW} / \mathrm{cm}^{2}$ in our clinical study.
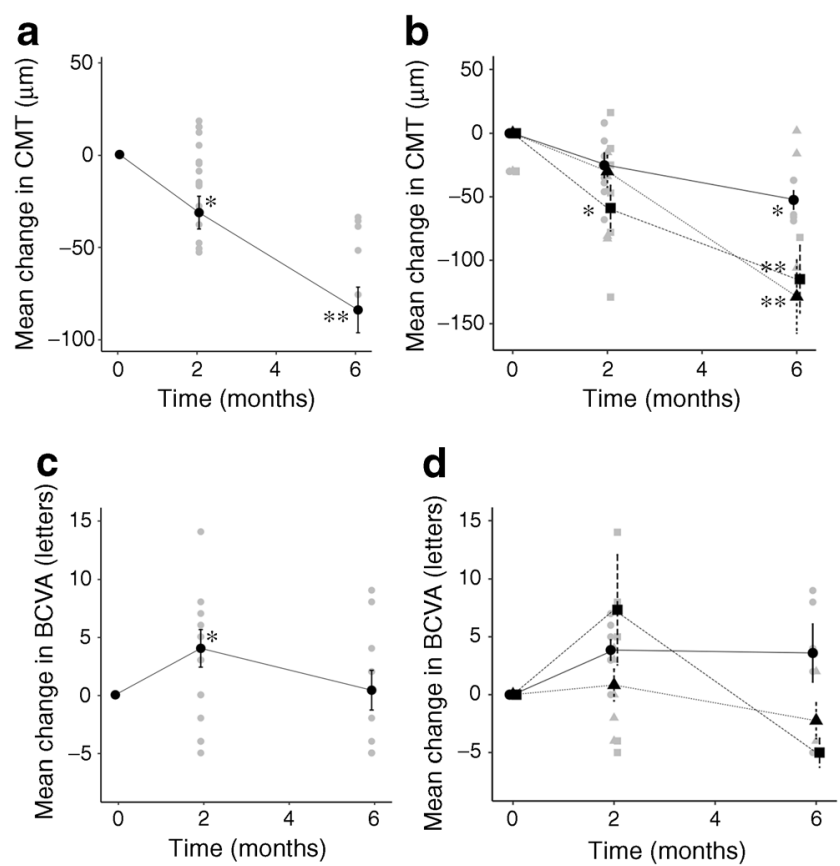

Fig. 6 Anatomical (a, b) and functional (c, d) outcomes 2 and 6 months after laser-delivered PBM in patients with centre-involving DME. (a, c) Overall changes in CMT (a) and BCVA (c) after PBM treatment across the three groups. There was significant reduction in CMT over time but without significant change in overall BCVA. (b, d) Changes in CMT and BCVA by group: group $1(n=7)$, circles $\left(25 \mathrm{~mW} / \mathrm{cm}^{2}\right)$; group $2(n=6)$, triangles $\left(100 \mathrm{~mW} / \mathrm{cm}^{2}\right)$; group $3(n=8)$, squares $\left(200 \mathrm{~mW} / \mathrm{cm}^{2}\right)$. At the month 2 time point, there was a significant reduction in CMT (b) in group 2 and group 3 but not in group 1 and no significant difference in BCVA in any treatment groups 6 months after PBM $(\mathbf{d})$. Data were expressed as mean \pm SD. $* p<0.05$ and $* * p<0.01$, compared by paired $t$ test of 2 and 6 months after PBM vs baseline. Dashed bars represent SD in the corresponding treatment groups 




Fig. 7 SD-OCT images and macular thickness maps of an eye before (ac), 2 months (d-f) and 6 months (g-i) after laser-delivered PBM at a setting of $100 \mathrm{~mW} / \mathrm{cm}^{2}$ (group 2). There was resolution of the intraretinal fluid at month 2 and the macula remained dry at 6 months without additional intervention. (c, f, i) Black numbers in each sector represent averaged thickness in sector in $\mu \mathrm{m}$, red numbers represent volume in $\mathrm{mm}^{3}$. Scale bars, $400 \mu \mathrm{m}$

$[10,26]$. Photoreceptor inner segments are rich in mitochondria [27, 28]. We found that Müller cell disruption led to decreased photoreceptor mitochondrial membrane potential, suggesting that mitochondrial dysfunction is one of the causes of the photoreceptor degeneration that follows Müller cell disruption. We also found that PBM enhanced the photoreceptor mitochondrial membrane potential and protected Müller cells and photoreceptors. These results are consistent with previous findings that PBM protects photoreceptors in animal models of light-induced photoreceptor injury [11, 29, 30], suggesting that PBM might be a way to protect photoreceptors from degeneration [3].

Since LED-delivered PBM emits non-coherent irradiation that may become a barrier to clinical translation, we next developed a $670 \mathrm{~nm}$ retinal laser to deliver precise PBM. We found that laser-delivered PBM enhanced metabolic activity, increased oxygen consumption rate (OCR), enhanced mitochondrial function and protected Müller cells against 


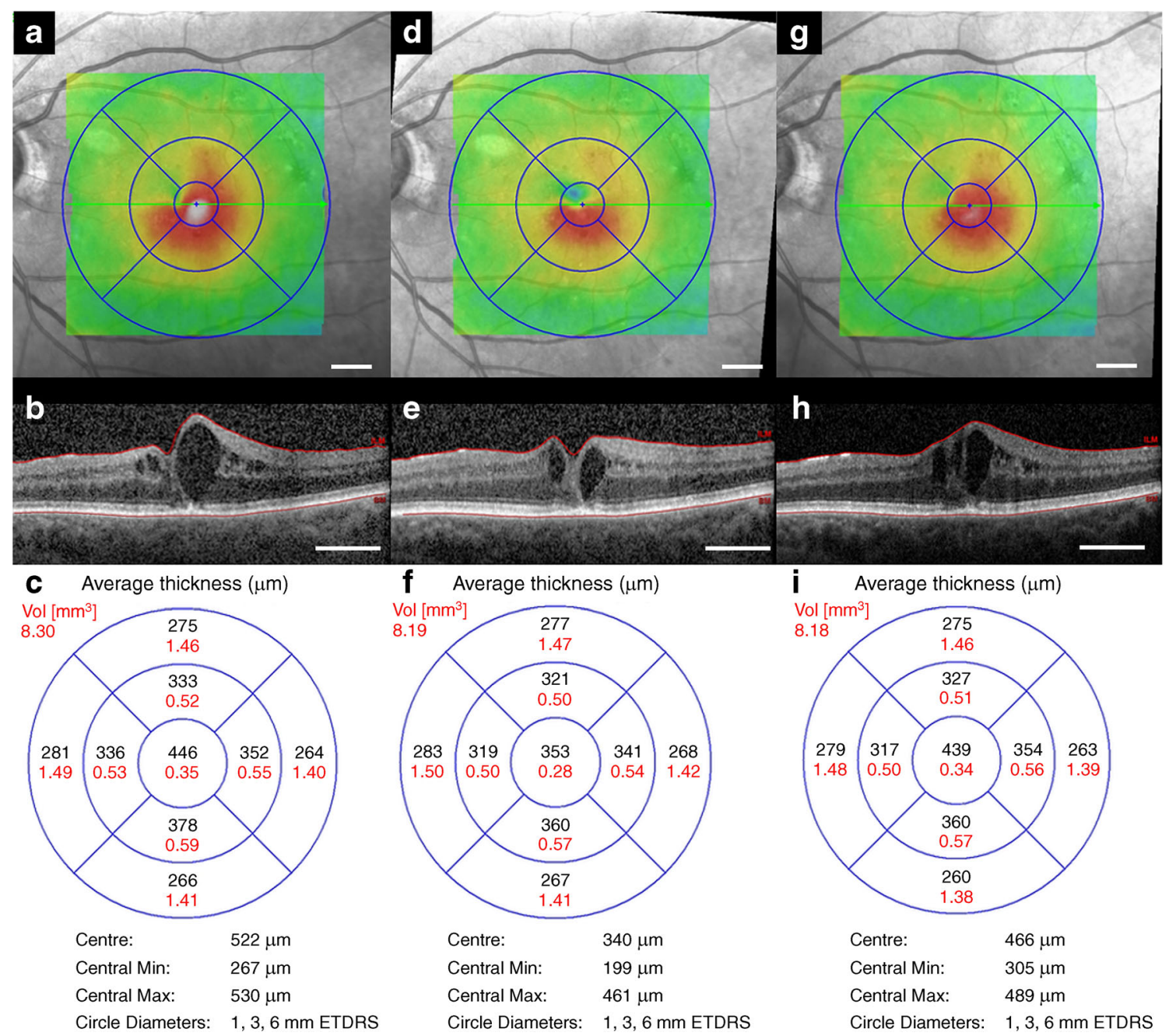

Fig. 8 SD-OCT images and macular thickness maps of an eye before (ac), 2 months (d-f) and 6 months $(\mathbf{g}-\mathbf{i})$ after laser-delivered PBM at a setting of $200 \mathrm{~mW} / \mathrm{cm}^{2}$ (group 3). The macula initially appeared to respond to PBM therapy at 2 months with reduction in retinal thickness

and intraretinal cysts (e) but there was recurrence at 6 months with increase in intraretinal cysts and overall retinal thickness $(\mathbf{h})$. (c, f, i) Black numbers in each sector represent averaged thickness in sector in $\mu \mathrm{m}$, red numbers represent volume in $\mathrm{mm}^{3}$. Scale bars, $400 \mu \mathrm{m}$

oxidative stress in vitro, further confirming our earlier finding that PBM protected Müller cells in our transgenic mice. The beneficial effects of PBM on protecting photoreceptors may involve multiple mechanisms. Lu et al reported that PBM reduced the expression of proinflammatory cytokines and decreased photoreceptor loss in light-induced photoreceptor degeneration [11]. Other potential mechanisms include stimulating expression of neurotrophic factors [31], decreasing production of reactive oxygen species $[10,26]$, regulating anti-apoptotic and pro-apoptotic mediators [32], suppressing inflammation $[11,30]$ and activating transcription factors to regulate gene expression $[10,33]$.

DME is characterised by fluid accumulation in the macula resulting from an imbalance in cellular fluid movement. Since there is no accessible animal model that replicates DME found in humans, we tested the effect of PBM on both the focal and diffuse vascular leakage that follows induced disruption of Müller cells [17, 19] and found that PBM reduced retinal vascular leakage. We acknowledge that focal intense vascular leakage in our transgenic mice is due to the development of intraretinal neovascularisation $[17,18,20]$ rather than breakdown of the BRB. These transgenic mice may not be an exact model of DME in humans; however, the diffuse retinal vascular leakage that we quantitatively measured and found to be reduced by PBM is similar to the features of DME in humans.

Multiple mechanisms may account for the reduced retinal vascular leakage after PBM in transgenic mice with induced Müller cell disruption. We found that PBM protected Müller cells in vivo and in vitro. Improved Müller cell survival and function may attenuate retinal vascular leakage because Müller cells are involved in the formation of the inner BRB and regulation of retinal homeostasis $[3,11]$. We previously found that patchy ablation of Müller cells led to activation of the remaining Müller cells and infiltration of microglia and macrophages [17-20]. Recent studies indicate that PBM inhibits Müller cell activation and reduces recruitment of 


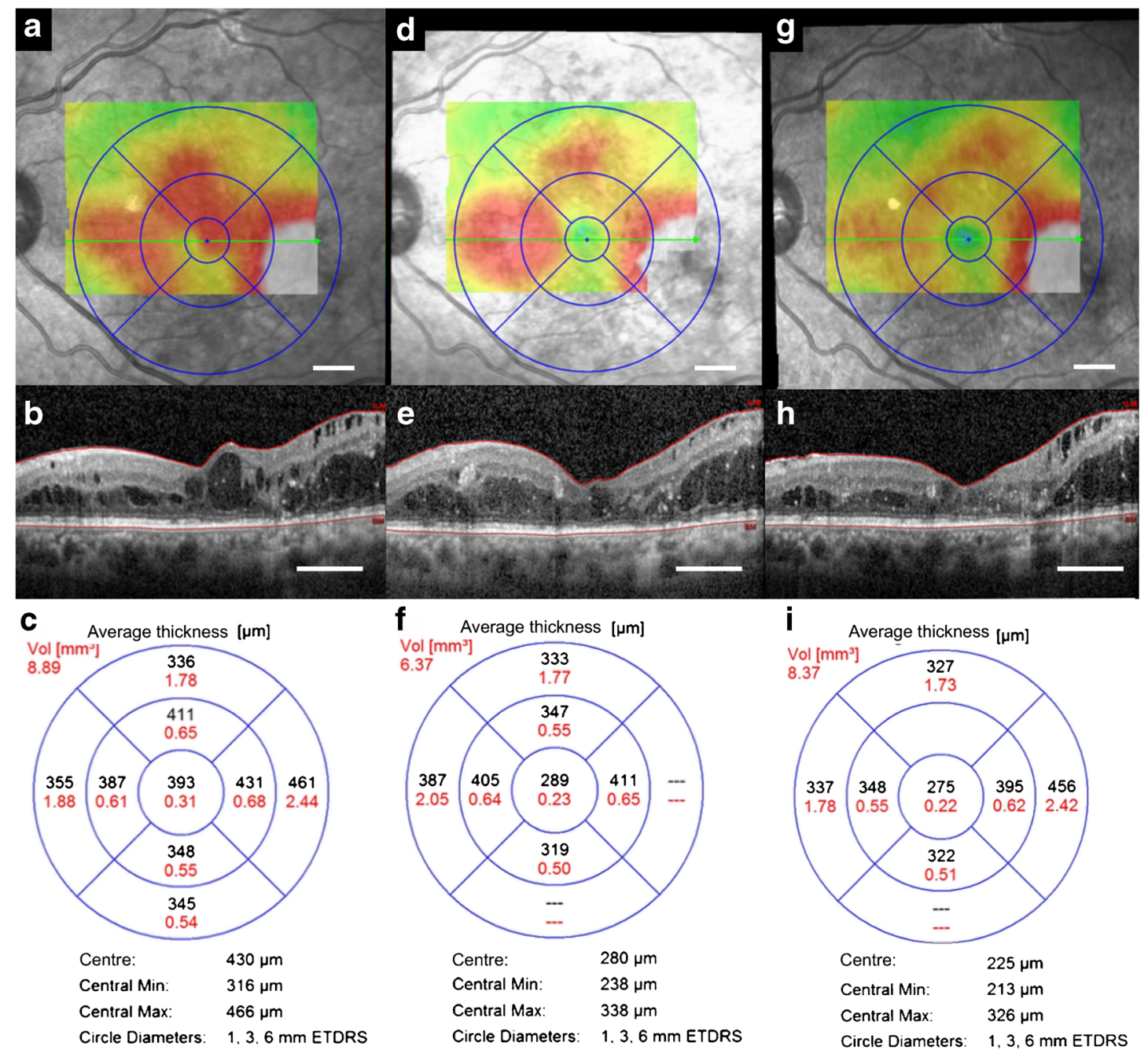

Fig. 9 SD-OCT images and macular thickness maps of an eye before (ac), 2 months $(\mathbf{d}-\mathbf{f})$ and 6 months $(\mathbf{g}-\mathbf{i})$ after laser-delivered PBM at a setting of $25 \mathrm{~mW} / \mathrm{cm}^{2}$ (group 1). The macula appeared to respond to PBM therapy at 2 months with resolution of intraretinal fluid at the fovea and juxtafovea but persistent diffuse oedema was more pronounced in the 3 to $6 \mathrm{~mm}$ ring of the retina (e). The persistent macular oedema was

microglia and macrophages, leading to decreased expression of proinflammatory cytokines including chemokine (C-C motif) ligand 2 (CCL2), IL-1 $\beta$ and IL-6 in light-induced photoreceptor degeneration $[11,12]$. Upregulation of proinflammatory mediators is believed to actively contribute to breakdown of the BRB [3, 34]. We postulate that PBM may also inhibit retinal inflammation to improve the BRB in our transgenic mice. We have previously reported that the retinal vascular abnormalities resulting from Müller cell disruption were associated with overexpression of VEGF and proinflammatory cytokines [17-20, 35, 36] along with reduced tight junction protein claudin-5 [17]. Future research is warranted to use an extensive approach, such as RNA-sequencing analysis, to study the effects of PBM on differential expression of angiogenic factors, proinflammatory mediators and tight junction proteins in our transgenic mice. deemed sight threatening and additional anti-VEGF therapy was administered at month 4, which resulted in further resolution of the diabetic macular oedema (h). (c, f, i) Black numbers in each sector represent averaged thickness in sector in $\mu \mathrm{m}$, red numbers represent volume in $\mathrm{mm}^{3}$. Scale bars, $400 \mu \mathrm{m}$

We studied the safety of laser-delivered PBM in rat eyes before testing it clinically. There are occasional reports about the adverse effects of near-infrared laser at higher power settings. Application of an $808 \mathrm{~nm}$ diode laser transcranial to the brain cortex of rats up to $375 \mathrm{~mW} / \mathrm{cm}^{2}$ appeared safe, but tissue damage was observed at $750 \mathrm{~mW} / \mathrm{cm}^{2}$ [37]. With $500 \mathrm{~mW} / \mathrm{cm}^{2}$, we found no adverse effects in non-pigmented eyes but observed localised photoreceptor damage in some pigmented eyes. The underlying mechanism is unknown, but a photothermal response is most likely [38]. Based on the safety study in rats, we included two measures to reduce the risk of adverse events in clinical study: first, a central masked area of $1 \mathrm{~mm}$ diameter was incorporated within the $4.5 \mathrm{~mm}$ diameter treatment zone to spare the fovea; second, the maximum dosage for PBM was 
$200 \mathrm{~mW} / \mathrm{cm}^{2}$. No significant adverse events were observed in the clinical study.

The major finding from the clinical study was that laserdelivered PBM resulted in dose-dependent and long-term (6 months) reductions in CMT of eyes with centre-involving DME. As this was a single arm non-randomised pilot study, an objective primary outcome measure, change in CMT, was chosen to prevent any placebo effect that may occur from subjective measures such as visual acuity.

The groups receiving PBM at 100 or $200 \mathrm{~mW} / \mathrm{cm}^{2}$ had greater reduction in CMT than eyes receiving $25 \mathrm{~mW} / \mathrm{cm}^{2}$ 6 months post treatment, which was comparable to the reduction in CMT in eyes treated with conventional laser photocoagulation for DME [39-41] and slightly less than the reduction in CMT after monthly intravitreal injections of ranibizumab [40]. No eyes treated with the highest dose, $200 \mathrm{~mW} / \mathrm{cm}^{2}$, required rescue treatment throughout the course of the trial. Few other clinical trials have reported the clinical effects of PBM on DME, with most of the literature focused on in vitro and animal disease models $[13,14,42]$. A previous study using LED-delivered PBM in four patients with noncentre-involving DME [16] reported a similar reduction in macular thickness to what we observed.

Overall, there was only a small increase in visual acuity after 2 months, which was not sustained at 6 months. This may be due to lack of power to detect a difference rather than a real finding. The generally good starting vision, average of about 65-70 $\log$ MAR letters (Snellen equivalent of $6 / 15-6 / 12$ ) of eyes in this study, is also likely to have placed a 'ceiling' on vision gains [43].

A strength of the clinical study is that PBM was administered via a retinal laser in a standardised way by specialist ophthalmologists. One limitation of our clinical study was the small number of patients enrolled which did not provide enough power to assess change in BCVA as a primary outcome. Another limitation was the lack of standardised criteria for the administration of rescue standard of care, which was left to the discretion of the treating physicians. Questions that need addressing in future studies are whether PBM can be used as an adjunct therapy to improve the effectiveness and reduce the frequency of intravitreal injections of VEGF inhibitors, and how often PBM should be applied.

In conclusion, our preclinical studies indicate that PBM is effective in improving mitochondrial function in photoreceptors and Müller cells. PBM protected Müller cell loss and photoreceptor degeneration and reduced retinal vascular leakage resulting from induced Müller cell disruption. An open-label Phase IIa clinical trial suggested that laser-delivered PBM is a safe and potentially effective treatment for DME. Further investigation of PBM for DME is warranted with a larger, randomised, controlled, Phase II study, such as the one currently being conducted by the Diabetic Retinopathy Collaborative Research network (clinicaltrials.gov identifier: NCT03866473). Additional positive studies would lay the foundation for a definitive Phase III randomised controlled trial.

Data availability The datasets generated from the current study are available from the corresponding authors upon reasonable request. No applicable resources were generated or analysed during the current study.

Funding Preclinical studies were supported by grants from National Health and Medical Research Council of Australia (NH\&MRC, APP1028393) and the Ophthalmic Research Institute of Australia. The clinical trials were supported by grants from the Sydney Eye Hospital Foundation and Australian Federal Government Innovation Connections. MCG is supported by Sydney Medical School Foundation and an NH\&MRC Practitioner Fellowship (APP1103406). KYCT and EEC were supported by fellowships from Sydney Eye Hospital Foundation with funding from Bayer and Novartis. The study sponsors were not involved in the design of the study; the collection, analysis and interpretation of data; or writing the report and did not impose any restrictions regarding the publication of the report.

Authors' relationships and activities MCG has relevant financial activities with Novartis, Allergan, Roche and Bayer. The remaining authors declare that there are no relationships or activities that might bias, or be perceived to bias, their work.

Contribution statement WS, JPMW and GC designed laboratory studies. RJC and MCG designed clinical studies. WS, KYCT, JPMW, GC, JA, AV, EEC, SRL, MXY and SFB performed research, and analysed and interpreted data. WS, KYCT, JPMW, GC, RJC and MCG wrote the paper. All authors have reviewed the final version of the manuscript and approved it to be published. MCG and RJC are the guarantors of this work and, as such, had full access to all data in the study and take responsibility for the integrity of the data and the accuracy of the data analysis.

\section{References}

1. Klein R, Klein BE, Moss SE, Davis MD, DeMets DL (1984) The Wisconsin epidemiologic study of diabetic retinopathy. IV. Diabetic macular edema. Ophthalmology 91(12):1464-1474

2. Holekamp NM (2016) Overview of diabetic macular edema. Am J Manag Care 22(10 Suppl):s284-s291

3. Daruich A, Matet A, Moulin A et al (2018) Mechanisms of macular edema: beyond the surface. Prog Retin Eye Res 63:20-68. https:// doi.org/10.1016/j.preteyeres.2017.10.006

4. Vecino E, Rodriguez FD, Ruzafa N, Pereiro X, Sharma SC (2016) Glia-neuron interactions in the mammalian retina. Prog Retin Eye Res 51:1-40. https://doi.org/10.1016/j.preteyeres.2015.06.003

5. Spaide RF (2016) Retinal vascular cystoid macular edema: review and new theory. Retina 36(10):1823-1842. https://doi.org/10.1097/ IAE.0000000000001158

6. He Y, Ren XJ, Hu BJ, Lam WC, Li XR (2018) A meta-analysis of the effect of a dexamethasone intravitreal implant versus intravitreal anti-vascular endothelial growth factor treatment for diabetic macular edema. BMC Ophthalmol 18(1):121. https://doi.org/10.1186/ s12886-018-0779-1

7. Xu Y, Tan CS (2017) Safety and complications of intravitreal injections performed in an Asian population in Singapore. Int 
Ophthalmol 37(2):325-332. https://doi.org/10.1007/s10792-0160241-4

8. Falavarjani KG, Nguyen QD (2013) Adverse events and complications associated with intravitreal injection of anti-VEGF agents: a review of literature. Eye (Lond) 27(7):787-794. https://doi.org/10. 1038/eye.2013.107

9. Geneva, II (2016) Photobiomodulation for the treatment of retinal diseases: a review. Int J Ophthalmol 9(1):145-152. https://doi.org/ 10.18240/ijo.2016.01.24

10. Salehpour F, Mahmoudi J, Kamari F et al (2018) Brain photobiomodulation therapy: a narrative review. Mol Neurobiol 55(8):6601-6636. https://doi.org/10.1007/s12035-017-0852-4

11. Lu YZ, Fernando N, Natoli R, Madigan M, Valter K (2018) 670nm light treatment following retinal injury modulates Muller cell gliosis: evidence from in vivo and in vitro stress models. Exp Eye Res 169:1-12. https://doi.org/10.1016/j.exer.2018.01.011

12. Lu YZ, Natoli R, Madigan M et al (2017) Photobiomodulation with $670 \mathrm{~nm}$ light ameliorates Muller cell-mediated activation of microglia and macrophages in retinal degeneration. Exp Eye Res 165:78-89. https://doi.org/10.1016/j.exer.2017.09.002

13. Saliba A, Du Y, Liu H et al (2015) Photobiomodulation mitigates diabetes-induced retinopathy by direct and indirect mechanisms: evidence from intervention studies in pigmented mice. PLoS One 10(10):e0139003. https://doi.org/10.1371/journal.pone.0139003

14. Tang J, Du Y, Lee CA et al (2013) Low-intensity far-red light inhibits early lesions that contribute to diabetic retinopathy: in vivo and in vitro. Invest Ophthalmol Vis Sci 54(5):3681-3690. https://doi.org/10.1167/iovs.12-11018

15. Cheng Y, Du Y, Liu H et al (2018) Photobiomodulation inhibits long-term structural and functional lesions of diabetic retinopathy. Diabetes 67(2):291-298. https://doi.org/10.2337/db17-0803

16. Tang J, Herda AA, Kern TS (2014) Photobiomodulation in the treatment of patients with non-center-involving diabetic macular oedema. Br J Ophthalmol 98(8):1013-1015. https://doi.org/10. 1136/bjophthalmol-2013-304477

17. Shen W, Fruttiger M, Zhu L et al (2012) Conditional Müller cell ablation causes independent neuronal and vascular pathologies in a novel transgenic model. J Neurosci 32(45):15715-15727. https:// doi.org/10.1523/JNEUROSCI.2841-12.2012

18. Shen W, Lee SR, Araujo J et al (2014) Effect of glucocorticoids on neuronal and vascular pathology in a transgenic model of selective Muller cell ablation. Glia 62(7):1110-1124. https://doi.org/10. 1002/glia.22666

19. Shen W, Zhu L, Lee SR, Chung SH, Gillies MC (2013) Involvement of NT3 and P75(NTR) in photoreceptor degeneration following selective Muller cell ablation. J Neuroinflammation 10: 137. https://doi.org/10.1186/1742-2094-10-137

20. Shen W, Lee SR, Yam M et al (2018) A combination therapy targeting endoglin and VEGF-A prevents subretinal fibroneovascularization caused by induced Muller cell disruption. Invest Ophthalmol Vis Sci 59(15):6075-6088. https://doi.org/10. 1167/iovs. $18-25628$

21. Roehlecke C, Schumann U, Ader M et al (2013) Stress reaction in outer segments of photoreceptors after blue light irradiation. PLoS One 8(9):e71570. https://doi.org/10.1371/journal.pone.0071570

22. Wood JP, Mammone T, Chidlow G, Greenwell T, Casson RJ (2012) Mitochondrial inhibition in rat retinal cell cultures as a model of metabolic compromise: mechanisms of injury and neuroprotection. Invest Ophthalmol Vis Sci 53(8):4897-4909. https:// doi.org/10.1167/iovs.11-9171

23. R Development Core Team (2017) R: a language and environment for statistical computing. R Foundation for Statistical Computing, Vienna, Austria

24. Kokkinopoulos I, Colman A, Hogg C, Heckenlively J, Jeffery G (2013) Age-related retinal inflammation is reduced by $670 \mathrm{~nm}$ light via increased mitochondrial membrane potential. Neurobiol Aging
34(2):602-609. https://doi.org/10.1016/j.neurobiolaging.2012.04. 014

25. Hamblin MR (2018) Mechanisms and mitochondrial redox signaling in photobiomodulation. Photochem Photobiol 94(2):199-212. https://doi.org/10.1111/php.12864

26. Salehpour F, Ahmadian N, Rasta SH et al (2017) Transcranial lowlevel laser therapy improves brain mitochondrial function and cognitive impairment in $\mathrm{D}$-galactose-induced aging mice. Neurobiol Aging 58:140-150. https://doi.org/10.1016/j. neurobiolaging.2017.06.025

27. Litts KM, Zhang Y, Freund KB, Curcio CA (2018) Optical coherence tomography and histology of age-related macular degeneration support mitochondria as reflectivity sources. Retina 38(3):445461. https://doi.org/10.1097/IAE.0000000000001946

28. Xie W, Zhao M, Tsai SH et al (2018) Correlation of spectral domain optical coherence tomography with histology and electron microscopy in the porcine retina. Exp Eye Res 177:181-190. https://doi. org/10.1016/j.exer.2018.08.003

29. Qu C, Cao W, Fan Y, Lin Y (2010) Near-infrared light protect the photoreceptor from light-induced damage in rats. Adv Exp Med Biol 664:365-374. https://doi.org/10.1007/978-1-4419-1399-9_42

30. Albarracin R, Eells J, Valter K (2011) Photobiomodulation protects the retina from light-induced photoreceptor degeneration. Invest Ophthalmol Vis Sci 52(6):3582-3592. https://doi.org/10.1167/ iovs.10-6664

31. Zhang J, Liu R, Kuang HY, Gao XY, Liu HL (2017) Protective treatments and their target retinal ganglion cells in diabetic retinopathy. Brain Res Bull 132:53-60. https://doi.org/10.1016/j. brainresbull.2017.05.007

32. Wang R, Dong Y, Lu Y et al (2018) Photobiomodulation for global cerebral ischemia: targeting mitochondrial dynamics and functions. Mol Neurobiol. https://doi.org/10.1007/s12035-018-1191-9

33. Jere SW, Houreld NN, Abrahamse H (2018) Photobiomodulation at $660 \mathrm{~nm}$ stimulates proliferation and migration of diabetic wounded cells via the expression of epidermal growth factor and the JAK/ STAT pathway. J Photochem Photobiol B 179:74-83. https://doi. org/10.1016/j.jphotobiol.2017.12.026

34. Mesquida M, Drawnel F, Fauser S (2019) The role of inflammation in diabetic eye disease. Semin Immunopathol 41(4):427-445. https://doi.org/10.1007/s00281-019-00750-7

35. Chung SH, Gillies M, Sugiyama Y et al (2015) Profiling of microRNAs involved in retinal degeneration caused by selective Muller cell ablation. PLoS One 10(3):e0118949. https://doi.org/ 10.1371/journal.pone.0118949

36. Chung SH, Gillies M, Yam M, Wang Y, Shen W (2016) Differential expression of microRNAs in retinal vasculopathy caused by selective Muller cell disruption. Sci Rep 6:28993. https://doi.org/10.1038/srep28993

37. Ilic S, Leichliter S, Streeter J et al (2006) Effects of power densities, continuous and pulse frequencies, and number of sessions of lowlevel laser therapy on intact rat brain. Photomed Laser Surg 24(4): 458-466. https://doi.org/10.1089/pho.2006.24.458

38. Youssef PN, Sheibani N, Albert DM (2011) Retinal light toxicity. Eye (Lond) 25(1):1-14. https://doi.org/10.1038/eye.2010.149

39. Do DV, Schmidt-Erfurth U, Gonzalez VH et al (2011) The DA VINCI study: phase 2 primary results of VEGF Trap-Eye in patients with diabetic macular edema. Ophthalmology 118(9): 1819-1826

40. Nguyen QD, Shah SM, Khwaja AA et al (2010) Two-year outcomes of the ranibizumab for edema of the mAcula in diabetes (READ-2) study. Ophthalmology 117(11):2146-2151

41. Mitchell P, Bandello F, Schmidt-Erfurth U et al (2011) The RESTORE study: ranibizumab monotherapy or combined with laser versus laser monotherapy for diabetic macular edema. Ophthalmology 118(4):615-625 
42. Eells JT, Gopalakrishnan S, Valter K (2016) Near-infrared photobiomodulation in retinal injury and disease. Adv Exp Med Biol 854:437-441

43. Sophie R, Lu N, Campochiaro PA (2015) Predictors of functional and anatomic outcomes in patients with diabetic macular edema treated with ranibizumab. Ophthalmology 122(7):1395-1401. https://doi.org/10.1016/j.ophtha.2015.02.036

Publisher's note Springer Nature remains neutral with regard to jurisdictional claims in published maps and institutional affiliations. 